\title{
Identification of germ cell-specific VASA and IFITM3 proteins in human ovarian endometriosis
}

Nicolas A. Fraunhoffer ${ }^{1,2,3^{*+}}$, Analía Meilerman Abuelafia ${ }^{1,3+}$, Inés Stella ${ }^{3}$, Silvia Galliano ${ }^{3,4}$, Marcela Barrios ${ }^{3}$ and Alfredo D. Vitullo 1,2

\begin{abstract}
Background: Endometriosis is a gynaecological disorder that affects 6-10 \% of female population. It is characterized by the presence of endometrial tissue outside the uterus, most often in the pelvic peritoneum or ovaries. Recent studies have indicated that mesenchymal endometrial stem cells might get involved in endometriosis progression. Although germ line stem cells have been proved to exist in the ovary, their involvement in ovarian endometriosis has not been investigated. In this preliminary report we aimed to identify germinal stem cell markers in ovarian endometriosis.

Findings: Ten paraffin-embedded ovarian endometriosis samples were screened for germ cell-specific proteins DDX4 (VASA) and IFITM3, and its relation with stem cell marker OCT4, proliferation marker PCNA and estrogen receptor alpha (ESR1), by immunohistochemistry, immunofluorescence and PCR. DDX4 and IFITM3 proteins were expressed in isolated cells and clusters of cells in the cortical region of ovarian endometriotic cysts. DDX4 and IFITM3 co-localized in cells from endometriotic stroma, and DDX4/FITM3-expressing cells were positive for ESR1, OCT4 and PCNA. No cells expressing neither DDX4 nor IFITM3 were detected in normal endometrial tissue.

Conclusion: The identification of germ cell-specific proteins DDX4 and IFITM3 provides the first evidence of ovarian-sourced cells in ovarian endometriotic lesions and opens up new directions towards understanding the still confusing pathogenesis of endometriosis.
\end{abstract}

Keywords: Ovarian endometriosis, Ovarian stem cells, DDX4, IFITM3

\section{Findings}

\section{Introduction}

Endometriosis is an estrogen-dependent benign chronic and multifactorial gynaecological disorder, characterized by the presence of endometrial tissue outside the uterus, most often in the pelvic peritoneum or ovaries $[1,2]$. Its prevalence is estimated to be $6-10 \%$ in the general female population and $35-50 \%$ in patients with infertility [1]. The lesions in the ovaries are predominantly hemorrhagic and characterized by invagination and invasion of the

\footnotetext{
* Correspondence: fraunhoffer.nicolas@maimonides.edu

${ }^{\dagger}$ Equal contributors

'Centro de Estudios Biomédicos, Biotecnológicos, Ambientales y Diagnóstico, CEBBAD- Universidad Maimónides, Hidalgo 775, Buenos Aires C1405BCK,

Argentina

${ }^{2}$ Consejo Nacional de Investigaciones Científicas y Técnicas,

CONICET-Argentina, Buenos Aires, Argentina

Full list of author information is available at the end of the article
}

endometrium into the ovarian cortex [3]. Endometriosis was first described by Carl von Rokitansky [4] in 1860; however, it still remains an enigmatic disease. Several theories have been proposed regarding the pathogenesis of endometriosis. The most accepted one is the "back flow" theory (retrograde menstruation) proposed by John Sampson [5] in 1925, which suggests that endometrial fragments in menstrual blood are taken over through the tubal pavilion into the peritoneal cavity initiating an endometriosis lesion. Recently, it has been postulated that endometriosis can arise from a small population of mesenchymal stem/stromal cells (eMSC) residing in the endometrial tissue [6,7]. This point of view was supported by the identification of undifferentiating markers such as C-KIT and OCT4 into the endometrial and ectopic endometriosis tissues $[8,9]$.

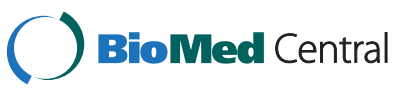

(c) 2015 Fraunhoffer et al. Open Access This article is distributed under the terms of the Creative Commons Attribution 4.0 International License (http://creativecommons.org/licenses/by/4.0/), which permits unrestricted use, distribution, and reproduction in any medium, provided you give appropriate credit to the original author(s) and the source, provide a link to the Creative Commons license, and indicate if changes were made. The Creative Commons Public Domain Dedication waiver (http://creativecommons.org/publicdomain/zero/1.0/) applies to the data made available in this article, unless otherwise stated. 
In the last 10 years, a long-held dogma proposing that the mammalian ovary has a finite, non-renewable oocyte pool has been challenged by the finding, in the adult mouse ovary, of a small population of germ line stem cells which could differentiate into oogonia, enter meiosis and contribute to oocyte replenishment [10]. Since then, evidence claimed to be for and against the possibility of oogenesis de novo in the adult mammalian ovary has accumulated [11]. Whether germ line stem cells contribute to oogenesis and follicle formation in vivo has not been proven yet [12]. However, germ line stem cells appear to exist in the adult ovary as shown by independent investigations in human, mouse and rat [13-15]. Moreover, isolated germ line stem cells can be manipulated in vitro to give rise to offspring after transplantation [13].

Whether, and how, germ line ovarian stem cells might contribute to the establishment and progression of ovarian endometriosis has not been yet investigated. In this study, we looked for the presence of ovarian stem cells in ovarian endometriosis lesions. We identified cells expressing VASA (DDX4) and IFITM3 germ line-specific markers known to be implicated in different cellular processes including germcell homing and maturation [16, 17].

\section{Materials and methods}

\section{Patients and samples}

This study was reviewed and approved by the Research Ethics Committee of Universidad Maimónides and the Ethics Committee from Clínica San Nicolás, Buenos Aires province, Argentina. Clinical paraffin-embedded samples of endometriosis and normal endometrial tissues were obtained from the repository of the Pathology Department of the Hospital Eva Perón, Buenos Aires province, Argentina. Endometriosis samples $(n=10)$ belonged to patients aged between 18 and 34 years, and endometrial tissues $(n=4)$ from patients aged between 32 and 45 years old, undergoing hysterectomy for benign pathologies.

\section{Immunohistochemistry}

Samples were baked overnight at $60{ }^{\circ} \mathrm{C}$, dewaxed in xylene and hydrated through a decreasing ethanol series (100, 80, and $50 \%$ ). After $10 \mathrm{~min}$ in PBS, the heat-induced epitope retrieval was performed by thermic bath at $96{ }^{\circ} \mathrm{C}$ in $10 \mathrm{mM}$ sodium citrate (pH 6) during $20 \mathrm{~min}$. Endogenous peroxidase activity was blocked with $3 \% \mathrm{H}_{2} \mathrm{O}_{2}$ in methanol for $30 \mathrm{~min}$, and washed twice in $0.01 \%$ Tween 20 in PBS buffer (PBS-T) (pH 7.4). After that, sections were blocked with $1.5 \%$ blocking serum solution (from ABC Vectastain Elite Kit, Vector Laboratories, Burlingame, USA) in PBS-T, for $30 \mathrm{~min}$. Slides were incubated with the primary antibody overnight at $4{ }^{\circ} \mathrm{C}$. Primary antibodies used included rabbit polyclonal anti-DDX4 IgG (1:200; Abcam, Cambridge, UK), and anti-IFITM3 (1:300; Abcam, Cambridge, UK).
Secondary antibody used was a goat anti-rabbit IgG (ABC Vectastain Elite Kit, Vector Laboratories, Burlingame, USA) for $30 \mathrm{~min}$ at room temperature followed by incubation with avidin-biotinn complex (ABC Vectastain Elite Kit, Vector Laboratories, Burlingame, USA) for additional $30 \mathrm{~min}$ at room temperature. The reaction was visualized with 3,3'- diaminobenzidine chromogen containing nickel salt (DAB Kit, Vector laboratories, Burlingame, USA). The sections were dehydrated, and coverslipped. Images were captured and analyzed using an optic microscope (BX40, Olympus Optical Corporation, Tokyo, Japan), with a digital camera (390CU 3.2 Megapixel CCD Camera, Micrometrics, Spain).

\section{Immunofluorescence and co-localization}

Paraffin sections were dewaxed in xylene and hydrated through decreasing ethanol. After $10 \mathrm{~min}$ in PBS, the heatinduced epitope retrieval was performed by thermal bath at $96{ }^{\circ} \mathrm{C}$ in $10 \mathrm{mM}$ sodium citrate at $\mathrm{pH} 6$ during $20 \mathrm{~min}$. After that, sections were blocked with blocking serum solution (Vector Laboratories, Burlingame, USA) diluted in $1.5 \%$ PBS-T for $30 \mathrm{~min}$. Slides were incubated with the primary antibody overnight at $4{ }^{\circ} \mathrm{C}$. Primary antibodies used included rabbit polyclonal Ig-G anti DDX4 (1:200; Abcam, Cambridge, UK), anti IFITM3 (1:300; Abcam, Cambridge, UK), anti OCT4 (1:300; Abcam, Cambridge, UK), anti PCNA (1:300; Abcam, Cambridge, UK), anti ESR1 (1:100; Santa Cruz Biotechnology Inc., Dallas, Texas, USA), and mouse monoclonal Ig-G anti CD45 (1:100; Dako, Copenhagen, Denmark). Secondary antibodies used were goat anti-rabbit FITC (1:500; Chemicon, EMD Millipore Corporation, Billerica, Massachusetts, USA), donkey anti-rabbit Alexa 555 (1:600; Invitrogen, Life Technologies Corporation, Carlsbad, California, USA), and goat anti-mouse FITC (1:300; Chemicon, EMD Millipore Corporation, Billerica, Massachusetts, USA) for $60 \mathrm{~min}$ at room temperature. The slides were counterstained with mounting medium for fluorescence with DAPI (H-1200; Vector Laboratories, Burlingame, USA). Negative controls were performed by omitting the primary antibody. Images were analyzed using an optic microscope (Olympus BX40) and captured with an attached digital camera (390CU 3.2 Megapixel CCD Camera, Micrometrics, Spain). Colon and ovary sections were used as positive control for IFITM3 and DDX4 antibodies, respectively.

Co-localization was performed initially in the same way as immunofluorescence, but after the first secondary antibody, the slides were rinsed twice with PBS-T for $10 \mathrm{~min}$ each. Then, the sections were blocked with blocking serum solution (Vector Laboratories, Burlingame, USA) diluted in $1.5 \%$ in PBS-T for $30 \mathrm{~min}$. After that, the slides were incubated with a second primary antibody overnight at $4{ }^{\circ} \mathrm{C}$ and then washed and incubated with the appropriate secondary antibody for 
$60 \mathrm{~min}$ at room temperature. Finally, slides were counterstained as indicated above.

\section{RNA extraction and RT-PCR}

Total RNA was extracted from paraffin embedded samples using the RNeasy FFPE kit (Qiagen, Hilden, Germany). The primers used for RT-PCR were as follows: DDX4_F:5'-AGAAAGTAGTGATACTCAAGGAC CA-3'; DDX4_R:5'-TGACAGAGATTAGCTTCTTCAA AAGT-3'; IFITM3_F:5'-CTGTCCAAACCTTCTTCTC TCC-3'; IFITM3_R:5'-GTAGGCGAATGCTATGAAGC C-3'. The RT-PCR was performed using QIAGEN One-step RT-PCR kit (Qiagen, Hilden, Germany).

\section{Results}

Identification of DDX4 and its association with hormonal, proliferation and stem cell markers

All samples were first inspected for general histology by hematoxylin-eosin (HE) staining and subjected to exploratory immunohistochemistry (IHC) for DDX4 and IFITM3 markers (Fig. 1). Although in some cases a clean HE was observed (Fig. 1a), most of the samples showed important amounts of hemorrhagic debris (Fig. 1b) yielding unspecific precipitates in IHC (Fig. 1c, d). However, a thorough inspection led to identify sparse cells displaying suspected specific signals both for IFITM3 (Fig. 1c) and DDX4 (Fig. 1d) mostly located near the borders of the endometriotic
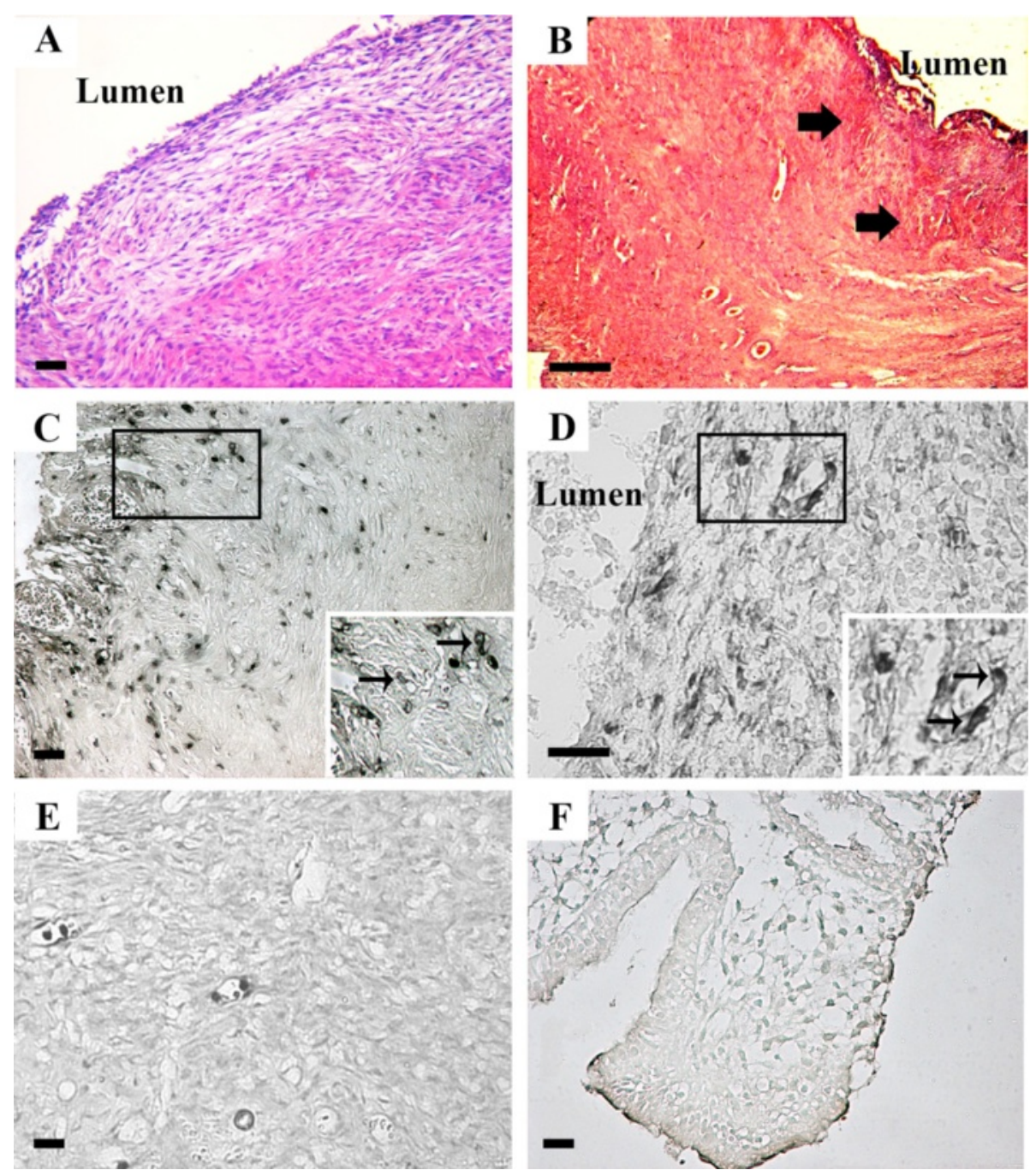

Fig. 1 General histology and immunohistochemistry for IFITM3 and DDX4 proteins in endometriotic cysts. a Hematoxylin-eosin general view of the wall of the endometriotic cyst, $\mathbf{b}$. General view of an endometriotic cyst showing large amounts of haemorrhagic debris (arrows), c. General view of IFITM3 immunodetection with detection of sparse cells with specific signals (inset), $\mathbf{d}$. DDX4 immunohistochemistry also enabled to detect dispersed cells showing positive reaction (inset), e. Normal endometrial tissue showing no positive cells for IFITM3, and f. Normal endometrial tissue negative for DDX4 immunohistochemistry. Bar $=50 \mu \mathrm{m}$ 
cyst. No cells indicating a possible specific signal were detected in control endometrial tissue both for IFITM3 and DDX4 proteins (Fig. 1e, f).

All samples were then thoroughly analyzed by immunofluorescence. In all endometriotic samples, DDX4positive cytoplasmic staining in stromal cells, isolated or in clusters, were undoubtedly detected (Fig. 2a). No DDX4-positive cells were detected in the 4 normal endometrial tissues inspected. Although not quantified, positive cells were low in numbers; however, samples from younger patients seemed to display higher numbers since positive cells were more easily found. PCR-analysis confirmed DDX4-mRNA expression in endometriotic samples (Fig. 3c).

We further studied the relationship between DDX4 and the characteristic hyper-estrogenic hormonal environment of this disease analyzing the co-expression of DDX4 and ESR1. In all pathological samples, we observed ESR1 staining in the nucleus of DDX4positive cells (Fig. 2a). Additionally, DDX4-expressing

A
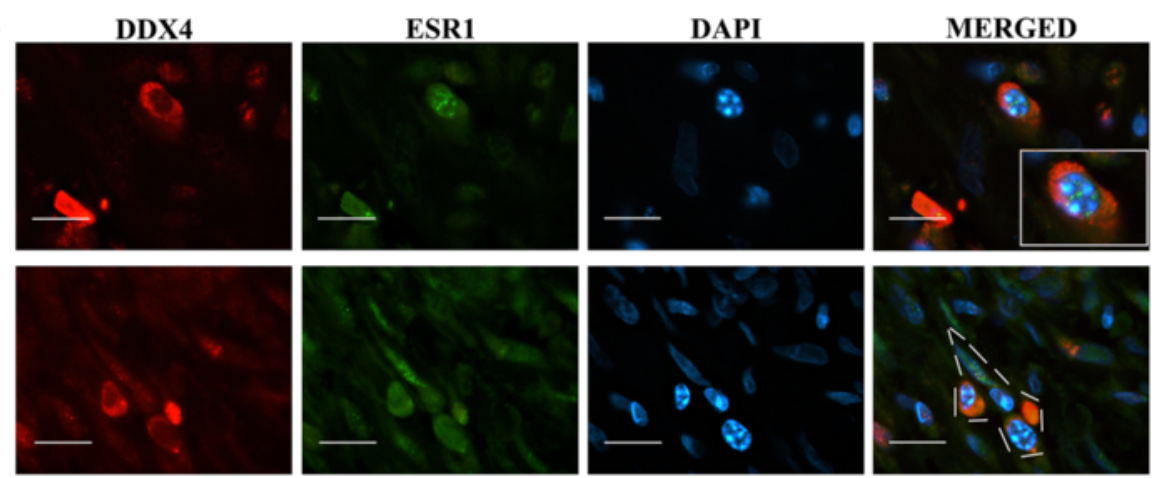

B

DDX4

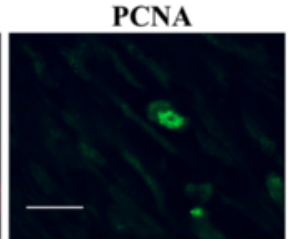

DAPI
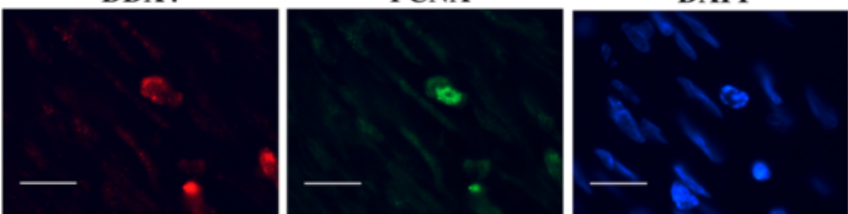

MERGED

C

DDX4

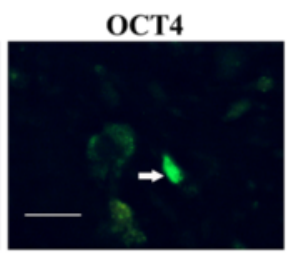

DAPI
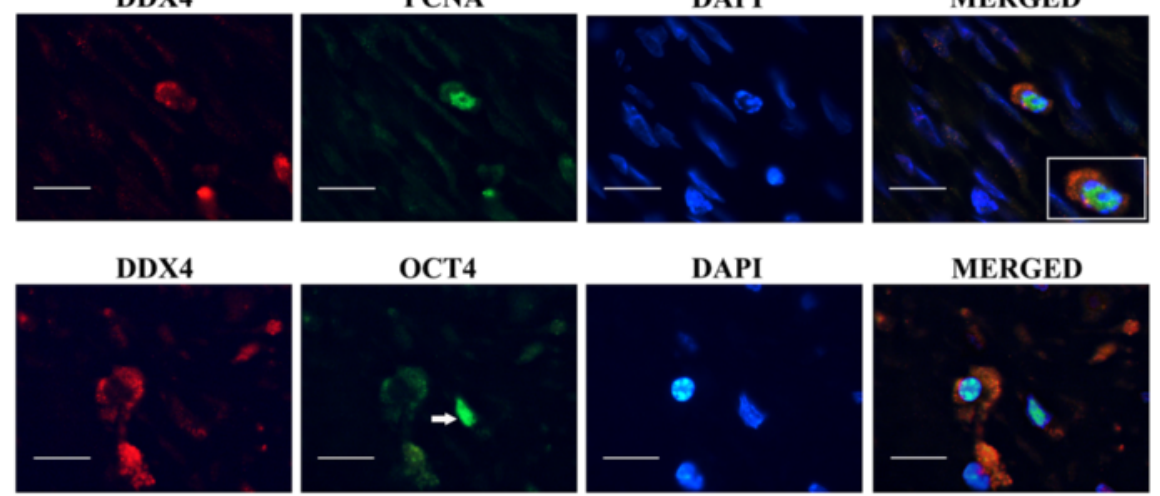

MERGED
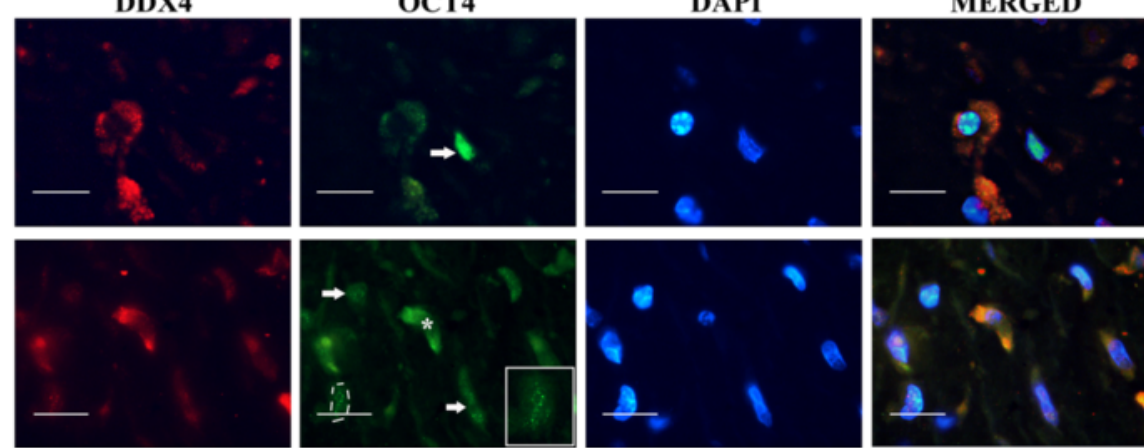

D

DDX4
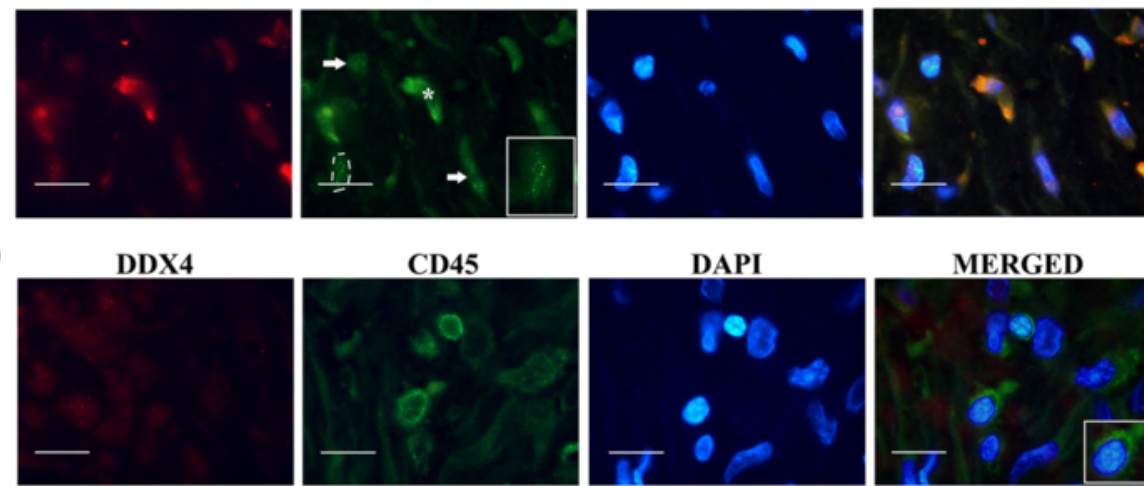

Fig. 2 Immunofluoresecent detection of DDX4 in ovarian endometriosis lesions and its relation to hormonal, stem cell and proliferation markers. a. Co-expression of DDX4 and ESR1. DDX4 was detected in cytoplasm of isolated cells and clusters of cells (dashed line). ESR1 was observed in the nucleus of the cells with positive cytoplasmatic staining for DDX4 (inset). $\mathbf{b}$ Co-expression of DDX4 and PCNA. DDX4 was observed in cytoplasm of cells with strong positive nuclear staining for PCNA (inset). c Co-expression of DDX4 and OCT4. OCT4 was mainly nuclear (arrows), but it also was observed in the cytoplasm (asterisk). The inset shows a detail of nuclear staining (dashed line). $\mathbf{d}$ CD45-positive cells did not show signal for DDX4 protein. Bar $=50 \mu \mathrm{m}$ 

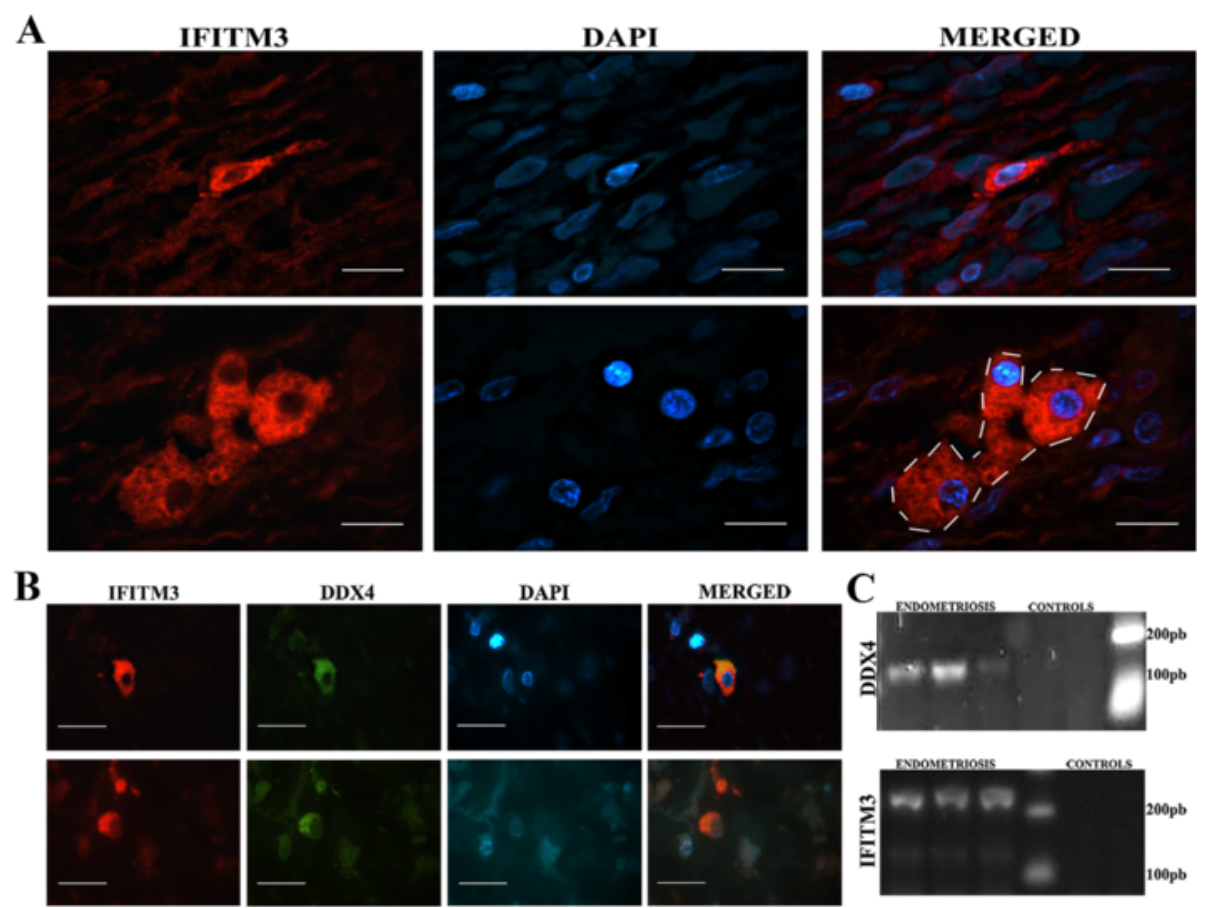

Fig. 3 Expression of IFITM3 in ovarian endometriosis lesions and RT-PCR for DDX4 and IFITM3. a IFITM3 was detected in cytoplasm of isolated cells and in clusters of cells (dashed line). $\mathbf{b}$ DDX4 and IFITM3 proteins co-localized in the cytoplasm in the same cells in endometriosis lesions. c DDX4 and IFITM3 were detected through RT-PCR in ovarian endometriosis. Endometrial tissue was negative. Bar $=50 \mu \mathrm{m}$

cells were positive for the proliferating marker PCNA (Fig. 2b) and, some of them, also showed a weak OCT4 cytoplasmic expression (Fig. 2c). On the other hand, cells expressing CD45 lymphocyte marker did not show signals for DDX4 (Fig. 2d).

\section{Identification of IFITM3 and its association with DDX4}

A homogeneous cytoplasm distribution of IFITM3 immunolabelling was found in isolated cells and clusters of cells in all endometriosis samples (Fig. 3a). Moreover, IFITM3 co-localized with DDX4 (Fig. 3b). No positive IFITM3 immunostaining was detected in normal endometrial tissue. The expression of IFITM3 in ovarian endometriosis lesions was confirmed by RT-PCR (Fig. 3c) and normal endometrial tissues were negative for IFITM3-mRNA.

\section{Discussion}

We identified DDX4 and IFITM3 proteins in isolated and clusters of cells in ovarian endometriosis lesions. DDX4 and IFITM3 are essential proteins for homing and maturation of germ cells $[18,19]$ that were used for isolation and purification of female germ line stem cells $[13,20]$. DDX4/IFITM3-positive cells in endometriotic lesions also expressed, although weakly, OCT4 protein, a transcriptional factor necessary for maintaining the selfrenewal and pluripotency phenotype of embryonic stem cells. Moreover, they expressed PCNA indicating self-renewal capacity and/or the mitotic activity of these cells. Thus, the finding of cells displaying germ cellspecific DDX4 and IFITM3 proteins suggests an ovarian origin, and as far as we could track in the literature this is the first evidence reported for ovarian-sourced cells in the endometrioma. In line with this, expression of pluripotency markers such as OCT4 and NANOG and the protoncogene $c$-KIT in stem-like cells in endometriosis have been described and related to the development of the disease and progression towards ovarian cancer [9, 21]. Nevertheless, the presence of ovarian germ line stem cells as contributors to endometriosis progression remains to be further studied through functional analysis in isolated DDX4/IFITM3-positive cells.

Alternatively to the prevailing theory of retrograde menstruation, it has been suggested that a small population of mesenchymal stem cells (eMSC) residing in the normal endometrial tissue may contribute to endometriosis progression $[6,7]$. It is not possible to rule out that DDX4/IFITM3-positive cells are related to eMSC since weak expression of OCT4 may indicate differentiation towards stromal cells. However, the absence of DDX4/ IFITM3-positive cells in normal endometrial tissue advocates in favour of an ovarian origin. Whatever the case may be, the identification of ovarian germ line and endometrial mesenchymal stem cells in endometriosis lesions adds up new ways in the understanding of this 
pathology whose pathogenesis still remains confusing. How stem cells may contribute to disease progression could be related to the hyperstrogenic environment that characterizes endometriosis, contributed by both systemic and locally synthesized estrogens [22]. Estrogen acts as a proliferation and differentiation agent not only in eutopic but also in ectopic endometrial cells [23]. In line with this, DDX4/IFITM3-positive cells were found to express ESR1 and revealed renewal activity by expressing PCNA.

Besides their essential role in germ line commitment, DDX4 and IFITM3 expression is also associated with other processes such as cell cycle progression $[24,25]$ and antiviral activity [26, 27]. IFITM3 is over expressed in different types of cancers, such as breast [28, 29], promoting epithelial-mesenchymal transition through the Wnt/ $\beta$-catenin signaling. On the other hand, DDX4 reduces the expression of 14-3-3 $\sigma$, which serves as a regulator for G2 checkpoint [25, 30]. Many reports have demonstrated the loss of expression of 14-3-3 $\sigma$ in human cancers [31, 32]. Furthermore, the relationship between endometriosis and cancer progression has been reported in endometriod epithelial ovarian cancer and ovarian clear cell carcinoma [33]. In this context, up regulation of DDX4 and IFITM3 proteins in ovariansourced stem cells, as well as OCT4 in eMSC, could correlate with the molecular pathway towards the malignant forms of the endometriosis lesion.

In conclusion, the data reported here identified DDX4and IFITM3-expressing cells, two germ line-specific proteins, in ovarian endometriotic lesions, most likely arising from ovarian-sourced stem cells, suggesting a possible involvement of ovarian stem cells in the development of the endometrioma. This finding opens new doors towards deepening the understanding of this pathology and its progression.

\section{Competing interests}

The authors declare that they have no competing interests.

\section{Authors' contribution}

NAF carried out immunohistochemistry, immunofluorescence and RT-PCR experiments, conceived and designed the study and drafted the manuscript. AMA participated in experiments and helped to draft the manuscript. IS and SG carried out selection of samples and histological characterization. MB participated in the design and coordination of the study. ADV participated in the design and coordination of the study and edited the final version of the manuscript. All authors read and approved the final manuscript.

\section{Acknowledgments}

This research was supported by Fundación Científica Felipe Fiorellino-Universidad Maimónides, Buenos Aires, Argentina. NAF is a recipient of a post-doctoral fellowship from the National Research Council, CONICET-Argentina. AMA is a doctoral fellow from Universidad Maimónides.

\section{Author details}

${ }^{1}$ Centro de Estudios Biomédicos, Biotecnológicos, Ambientales y Diagnóstico, CEBBAD- Universidad Maimónides, Hidalgo 775, Buenos Aires C1405BCK, Argentina. ${ }^{2}$ Consejo Nacional de Investigaciones Científicas y Técnicas, CONICET-Argentina, Buenos Aires, Argentina. ${ }^{3}$ Facultad de Medicina,
Universidad Maimónides, Buenos Aires, Argentina. ${ }^{4}$ Servicio de Anatomía Patológica, Hospital Eva Perón, Merlo, Buenos Aires, Argentina.

Received: 10 September 2015 Accepted: 2 October 2015

Published online: 07 October 2015

\section{References}

1. Giudice LC, Kao LC. Endometriosis. Lancet. 2004;364:1789-99.

2. Bellelis $P$, Podhaec $S$, Abrão MS. Environmental factors and endometriosis. Rev Assoc Med Bras. 2011;57:448-52.

3. Brosens I. Endometriosis and the outcome in vitro fertilization. Fert Steril. 2004;81:1198-200.

4. von Rokitansky C. Ueber Uterusdrusen-neubilding in Uterus- und Oarial-Sarcomen. Z KK Gesellsch Der Aerzte zu Wien. 1860;37:557-81.

5. Sampson JA. Inguinal endometriosis. Am J Obstet Gynecol. 1925;10:462-503.

6. Chan RW, Gargett CE. Identification of label-retaining cells in mouse endometrium. Stem Cells. 2006;24:1529-38.

7. Taylor RN. The future of endometriosis research: genomics or proteomics? Gynecol Obstet Invest. 2004;57:47-9.

8. Cervello I, Martinez-Conejero JA, Horcajadas JA, Pellicer A, Simon C. Identification, characterization and co-localization of label-retaining cell population in mouse endometrium with typical undifferentiated markers. Hum Reprod. 2007;22:45-51.

9. Pacchiarotti A, Caserta D, Sbracia M, Moscarini M. Expression of oct-4 and c-kit antigens in endometriosis. Fert Steril. 2011;95:1171-3.

10. Johnson J, Canning J, Kaneko T, Pru JK, Tilly JL. Germline stem cells and follicular renewal in the postnatal mammalian ovary. Nature. 2004;428:145-50.

11. Tilly JL, Niikura $Y$, Rueda BR. The current status of evidence for and against postnatal oogenesis in mammals: a case of ovarian optimism versus pessimism? Biol Reprod. 2009:80:2-12

12. Hummitzsch $\mathrm{K}$, Anderson RA, Wilhelm D, Wu J, Telfer EE, Russell DL, et al. Stem cells, progenitor cells and lineage decisions in the ovary. Endocrine Rev. 2015;36:65-91.

13. Zou K, Hou L, Sun K, Xie W, Wu J. Improved efficiency of female germline stem cell purification using fragilis-based magnetic bead sorting. Stem Cells Dev. 2011;20:2197-204.

14. White YA, Woods DC, Takai Y, Ishihara O, Seki H, Tilly JL. Oocyte formation by mitotically active germ cells purified from ovaries of reproductive-age women. Nat Med. 2012;18:413-21.

15. Zhou L, Wang L, Kang JX, Xie W, Li X, Wu C, et al. Production of fat-1 transgenic rats using a post-natal female germline stem cell line. Molec Hum Reprod. 2014;20:271-81.

16. Dawei $L$, Zhihai $P$, Huamei $T$, Ping $W$, Xiangyu $K$, Dongwang $Y$, et al. KLF4- Mediated negative regulation of IFITM3 expression plays a critical role in colon cancer pathogenesis. Clin Cancer Res. 2011;17:3558-68.

17. Yamija M, Wessel G. The multiple hats of Vasa: Its functions in the germline and in cell cycle progression. Molec Reprod Dev. 2011;78:861-7.

18. Castrillon DH, Quade BJ, Wang TY, Quigley C, Crum CP. The human VASA gene is specifically expressed in the germ cell lineage. Proc Natl Acad Sci U S A. 2000;97:9585-90.

19. Saitou M. Germ cell specification in mice. Curr Opin Genet Dev. 2009;19:386-95.

20. Zou K, Yuan Z, Yang Z, Luo H, Sun K, Zhou L, et al. Production of offspring from a germline stem cell line derived from neonatal ovaries. Nature Cell Biol. 2009;11:631-6.

21. Song Y, Xiao L, Fu J, Huang W, Wang Q, Zhang X, et al. Increased expression of the pluripotency markers sex-determining region Y-box 2 and Nanog homeobox in ovarian endometriosis. Reprod Biol Endocrinol. 2014;12:42.

22. Huhtinen K, Desai R, Stahle M, Salminen A, Handelsman DJ, Perheentupa A, et al. Endometrial and endometriotic concentrations of estrone and estradiol are determined by local metabolism rather than circulating levels. J Clin Endocrinol Metab. 2012;97:4228-35.

23. Bulun SE, Zeitoun KM, Takayama K, Sasano H. Estrogen biosynthesis in endometriosis: molecular basis and clinical relevance. J Molec Endocrinol. 2000;25:35-42.

24. Brem R, Oraslzlan-Szovik K, Foser S, Bohrmann B, Certa U. Inhibition of proliferation by $1-8 \mathrm{U}$ in interferon-alpha-responsive and non-responsive cell lines. Cell Molec Life Sci. 2003;60:1235-48.

25. Hashimoto H, Sudo T, Mikami Y, Otani M, Takano M, Tsuda H, et al. Germ cell specific protein VASA is over-expressed in ephithelial ovarian cancer and disrupts DNA damage-induced G2 checkpoint. Gynecol Oncol. 2008;111:312-9. 
26. Zhu H, Liu C. Interleukin-1 inhibits hepatitis C virus subgenomic RNA replication by activation of extracellular regulated kinase pathway. J Virol. 2003;77:5493-8.

27. Brass AL, Huang IC, Benita Y, John SP, Krishnan MN, Feeley EM, et al. The IFITM proteins mediate cellular resistance to influenza A H1N1 virus, West Nile virus, and dengue virus. Cell. 2009;139:1243-54.

28. Yang M, Gao H, Chen P, Jia J, Wu S. Knockdown of interferon-induced transmembrane protein 3 expression suppresses breast cancer cell growth and colony formation and affects the cell cycle. Oncol Reports. 2013;30:171-8.

29. Hu J, Wang S, Zhao Y, Guo Q, Zhang D, Chen J, et al. Mechanism and biological significance of the overexpression of IFITM3 in gastric cancer. Oncol Reports. 2014;32:2648-56.

30. Kim KH, Kang YJ, Jo JO, Ocks MS, Moon SH, Suh DS, et al. DDX4 (DEAD box polypeptide 4) colocalizes with cancer stem cell marker CD133 in ovarian cancers. Biochem Biophys Res Com. 2014:447:315-22.

31. Ferguson AT, Evron E, Umbrich CB, Pandita TK, Chan TA, Hermeking $H$, et al. High frequency of hipermethylation at the 14-3-3 sigma locus leads to gene silencing in breast cancer. Proc Natl Acad Sci U S A. 2000;97:6049-54.

32. Akahira J, Sugihashi Y, Suzuki T, Ito K, Niikura H, Moriya T, et al. Decreased expression of 14-3-3 sigma is associated with advanced disease in human epithelial ovarian cancer: its correlation with aberrant DNA methylation. Clin Cancer Res. 2004;10:2687-93.

33. Myong Cheol L, Kyoung-Chul C, So-Jin S, In Ho L, Kyung Taek L, Chi Heum C, et al. Clinical presentation of endometrioid epithelial ovarian cancer with concurrent endometriosis: a multicenter retrospective study. Cancer Epidemiol Biomark Prevent. 2010;19:398-404.

\section{Submit your next manuscript to BioMed Central and take full advantage of:}

- Convenient online submission

- Thorough peer review

- No space constraints or color figure charges

- Immediate publication on acceptance

- Inclusion in PubMed, CAS, Scopus and Google Scholar

- Research which is freely available for redistribution 